\title{
ANÁLISE DAS CAUSAS DE FISSURAS EM EDIFICAÇÃO RESIDENCIAL MULTIFAMILIAR EM PAREDES DE CONCRETO NO SUL DO BRASIL - ESTUDO DE CASO
}

\author{
MUNARETTO COPETTI, MARINA \\ Engenheira Civil \\ UFSM \\ RS, Brasil \\ marinamunaretto@hotmail.com
}

\author{
JOHANN KÜLZER, PAOLA NADINE \\ Engenheira Civil \\ URI \\ RS, Brasil \\ pnjoahnnk@gmail.com
}

\author{
PANNO, PATRÍCIA \\ Engenheira Civil \\ UNIPAMPA \\ RS, Brasil \\ panno.pati@gmail.com
}

\author{
MÜLLER,LAURA \\ Engenheira Civil \\ CYMi CONSTRUÇÕES E PARTICIPAÇÕES S.A. \\ MG, Brasil \\ muller.lauh@yahoo.com.br
}

\author{
SANTOS, CRISTIANE CARINE \\ Eng $^{\text {a }}$ Civil e Prof ${ }^{\text {a }}$ acadêmica \\ UFSM \\ RS, Brasil \\ cristianecdossantos@ hotmail.com
}

\section{RESUMO}

A concorrência imobiliária ligada à valorização dos terrenos nos centros urbanos tem exigido cada vez mais as empresas da construção civil a buscar empreendimentos de área menor e em maior quantidade. Como alternativa então desenvolveu-se o modelo de construção de parede de concreto. Nesse modelo, as paredes são moldadas no local, com o uso de formas moduladas e apresentam vantagens como rapidez de execução, redução de mão-de-obra, custos globais mais baixos, considerável desempenho, minimiza a geração de resíduos, além de produzir um modelo construtivo em escala, devido à industrialização do sistema. Mesmo com o avanço tecnológico das técnicas construtivas e o emprego de materiais de construção com maior controle de qualidade, ainda se observa um grande número de edificações apresentando patologias das mais variadas espécies. O presente trabalho apresenta uma investigação teórica sobre a técnica construtiva em paredes de concreto suas características e as formas mais frequentes de patologias que afetam esse tipo de edificação, especificamente a formação de fissuras. Tem como objetivo principal executar um estudo de caso em uma edificação residencial multifamiliar construída em parede de concreto, com a finalidade de identificar as fissuras existentes e determinar, por meio de sua forma, espessura e atividade, os mecanismos responsáveis pela sua formação e, deste modo, propor as técnicas corretivas mais adequadas a serem executadas, como determinar as medidas complementares necessária para preservar a estrutura da ação dos agentes patológicos.

Palavras-chave: parede de concreto, fissuras, estudo de caso.

\begin{abstract}
Real estate competition linked to the appreciation of land in urban centers has increasingly required construction companies to seek smaller and larger projects. Alternatively, the concrete wall construction model was developed. In this model, the walls are molded on site using modulated shapes and have advantages such as speed of execution, labor reduction, lower overall costs, considerable performance, minimizes waste generation, and produce a constructive scale model, due to the industrialization of the system. Even with the technological advancement of construction techniques and the use of building materials with greater quality control, there is still a large number of buildings with pathologies of the most varied species. This paper presents a theoretical investigation about the construction technique in concrete walls, its characteristics and the most frequent forms of pathologies that affect this type of building, specifically the formation of cracks. Its main objective is to carry out a case study in a multifamily residential building built in a concrete wall, in order to identify the existing cracks and to determine, by their shape, thickness and activity, the mechanisms responsible for their formation and, thus Thus, propose the most appropriate corrective techniques to be performed, such as determining the complementary measures necessary to preserve the structure of action of pathological agents.
\end{abstract}

Keywords: concrete wall, crack, case study 


\section{INTRODUÇÃO}

Dados oficiais da Caixa Econômica Federal mostram que o sistema aqui analisado, que utiliza paredes de concreto moldadas no local da obra, tem prevalecido no programa Minha Casa Minha Vida. Em 2014, a tecnologia estava presente em 36\% das unidades produzidas. Já no final de 2015, o percentual cresceu 52\% (SANTOS, 2016).

O sistema parede de concreto é uma tecnologia de construção industrializada e racionalizada que visa a melhoria da produtividade, velocidade, baixo custo e qualidade, indicado para construções com alta repetitividade (CORSINI, 2011; THIYAGARAJAN; ANNERSELVAM; NAGAMANI, 2017).

O principal programa de habitação popular brasileiro Minha Casa Minha Vida (MCMV) entregou 54\% das moradias com manifestações patológicas, segundo levantamento realizado pela Controladoria Geral da União (CGU) em parceria com o Ministério da Transparência em 77 empreendimentos e 1.472 unidades habitacionais em doze estados do país (BRASIL, 2017)

\section{PATOLOGIAS EM PAREDE DE CONCRETO}

As fissuras podem ser por causadas por retração, variação de temperatura, esforços mecânicos, recalques de fundação, movimentação higroscópica. Há doutrinadores que entendem que as fissuras podem ser ocasionadas pela retração do concreto, ausência de cura, uso de areia inapropriada, falta de juntas de dilatação e erro de cálculo estrutural. (THOMAZ, 2007).

As fissuras são um tipo de patologia com grande influência no comportamento deste tipo de revestimentos. O seu aparecimento afeta a capacidade de impermeabilização, que ao permitir o acesso da água e de outros agentes agressivos, reduz a durabilidade da fachada. Geralmente o surgimento das fissuras no concreto se torna visível após alguns anos, sendo assim, difícil para apontar com exatidão sua origem ou as causas. Na maioria das vezes, uma combinação de fatores podem ser os responsáveis pelo surgimento das fissuras.

As trincas e fissuras podem ter suas origens por falhas na execução tanto na etapa de lançamento e adensamento do concreto fresco (plástico) quanto após, já endurecido. Segundo Campagnolo (NẪ PUBLICADO, p. 141):

As fissuras no concreto fresco (não endurecido) podem ser decorrentes: de assentamentos diferenciais dentro da massa do concreto - assentamento plástico, de retração da superfície causada pela rápida evaporação da água dessecação superficial ou ainda pela movimentação das fôrmas

O aparecimento de trincas e fissuras logo na fase de execução de obra é um fator preocupante. São pontos de possível infiltração de agentes agressivos e muito possivelmente ocorra carbonatação do concreto no local, que pode despassivar as armaduras. A despassivação das armaduras é o primeiro passo para o início da corrosão das mesmas, outra manifestação patológica que prejudica a estrutura e que pode ocasionar em fissuras ainda maiores, paralelas à armadura corroída, por causa do descolamento causado pela redução da seção do aço (CAMPAGNOLO, NÃO PUBLICADO).

Locais com sistemas embutidos nas paredes (eletrodutos, caixas elétricas, etc.) devem ter seus espaçadores bem posicionados, a fim de evitar regiões sem o devido cobrimento de concreto, que podem ocasionar fissuras paralelas a estes sistemas. Estas fissuras, por mais que não representem perigos estruturais à parede, são regiões que podem ocasionar carbonatação e consequente despassivação da armadura do sistema.

\subsection{Fissuras}

A qualidade da execução do concreto, principalmente com relação às atividades de mistura, transporte, lançamento, adensamento e cura, é extremamente importante para minimizar a permeabilidade, evitando-se segregações, exsudação excessiva e formação de fissuras.(TUTIKIAN, 2007) A utilização de aditivos plastificantes ou incorporadores de ar é uma forma de reduzir a permeabilidade, uma vez que esses aditivos permitem a redução da quantidade de água na mistura, para uma mesma trabalhabilidade. A utilização de cimentos pozolânicos e de alto forno também contribui para a redução da permeabilidade.(MEHTA \& MONTEIRO, 2014) A fissuração, assim como a porosidade, também proporciona facilidades para que os agentes agressivos penetrem no concreto e iniciem sua ação destruidora na estrutura. As fissuras vão ocorrer sempre que a tensão de tração no concreto for maior do que a sua resistência à tração, que é reconhecidamente bastante baixa. Nas linhas que se seguem, apresentam-se os tipos de fissuras que ocorrem com maior freqüência na prática.(BRANDÃO \& PINHEIRO, 1998)

Diversas são as circunstâncias que podem provocar fissuração do concreto. As fissuras podem surgir mesmo antes da aplicação do carregamento e, inclusive, antes do endurecimento da massa. Elas podem ser causadas por movimentos gerados dentro do próprio concreto (assentamento plástico diferencial, retração plástica superficial, retração por 
secagem, movimentações de origem térmica), por expansão de materiais embutidos no concreto (corrosão das armaduras, reações álcali-agregado) ou ainda por condições externas impostas (carregamentos excessivos, vibrações não previstas no projeto, armaduras insuficientes ou mal posicionadas, recalque diferencial do solo de fundação), dentre outras causas. As fissuras que ocorrem antes do endurecimento do concreto, geralmente, resultam de assentamento plástico diferencial ou de retração plástica superficial. A formação dessas fissuras está relacionada diretamente com a exsudação, fenômeno caracterizado pelo deslocamento da água da mistura em direção à superfície, e com a velocidade de evaporação desta água. As fissuras devidas a assentamento plástico diferencial ocorrem quando há algum impedimento (proporcionado, por exemplo, pela presença de armadura ou de agregados muito grandes) ao assentamento da massa do concreto ainda plástico na fôrma.(BRANDÃO, 1998)

$\mathrm{O}$ assentamento dos materiais que compõem o concreto se deve à ação da gravidade e provoca o deslocamento da água e do ar não excluído pela vibração em direção à superfície. Tais fissuras podem ser evitadas mediante dosagem bem proporcionada com o mínimo slump praticável e adensamento adequado, que pode, inclusive, incluir revibração depois que as fissuras ocorrem. As fissuras por retração plástica superficial podem ocorrer se houver impedimento ao decréscimo de volume causado por evaporação excessivamente rápida da água da superfície quando o concreto ainda é plástico e não possui resistência. Tais fissuras começam a se formar quando o brilho da água desaparece da superfície do concreto, se a perda de água por evaporação for maior do que a quantidade de água provida pela exsudação.(NEVILLE, 2015)

Para prevenir o aparecimento dessas fissuras, recomenda-se controlar a temperatura do concreto quando a concretagem se dá em tempo quente, reduzir a velocidade do vento na superfície exposta e aumentar a sua umidade. As fissuras que ocorrem após o endurecimento da massa, porém antes de serem aplicadas as cargas, podem resultar de retração por secagem, movimentações de origem térmica ou de outras causas, tais como: reações álcali-agregado, corrosão das armaduras, ciclo gelo/degelo, ciclo alternado de molhagem e secagem, recalques diferenciais do solo de fundação etc. A retração por secagem corresponde a uma deformação do concreto a longo prazo, independentemente de aplicação de cargas, decorrente de redução do seu volume devido a perda de água por evaporação. Fissuras podem se formar se houver restrições ao movimento produzido pela retração. (MEHTA \& MONTEIRO, 2014)

Para evitá-las, recomenda-se dispor armadura especial para controle de fissuração, reduzir a relação água/cimento, promover cura adequada e utilizar juntas de contração convenientemente espaçadas. Movimentações de origem térmica são causas freqüentes de fissuras. Nas primeiras idades do concreto, devido ao calor liberado durante a hidratação do cimento, são gerados gradientes de temperatura entre o interior da massa e a superfície externa em contato com o ambiente. Este gradiente pode causar tensões capazes de provocar fissuração. (BRANDÃO, 1998)

Reduzir a temperatura do concreto durante o lançamento e controlar o calor de hidratação são medidas que auxiliam no combate à formação dessas fissuras. As movimentações de origem térmica podem ocorrer, também, nas estruturas em serviço. Um exemplo típico é representado pelas lajes de cobertura, submetidas a distribuições não uniformes de temperatura, decorrentes de variações climáticas durante o dia. Esta situação pode gerar tensões suficientes para causar fissuras, as quais, se não forem controladas por armadura adequada, podem ser consideradas inaceitável. (NEVILLE, 2015)

As fissuras excessivas que ocorrem após a aplicação do carregamento são devidas a falhas estruturais causadas por cargas excessivas ou vibrações não previstas no projeto, armaduras mal posicionadas ou insuficientes etc. Tais fissuras podem ser controladas mediante projeto bem elaborado. Percebe-se, do exposto, que o concreto, para ser durável, deve possuir elevada compacidade e ter sua fissuração controlada. (BRANDÃO, 1998)

Por meio deste trabalho, esclarece-se a natureza da patologia mais frequente encontrada nos edifícios de parede de concreto, as fissuras.

\section{METODOLOGIA}

Primeiramente, o levantamento das manifestações das patologias identificadas na obra analisada.

A metodologia do trabalho foi dividida em três etapas:

1. Realização de inspeções visuais dos apartamentos;

2. Análise dos problemas, quantitativamente e qualitativamente;

3. Investigação das possíveis causas dos problemas identificados;

O quadro 1 demonstra as principais características do edifício utilizado como estudo de caso. 
Quadro 1. Caracterização do empreendimento analisados no estudo de caso

\begin{tabular}{|c|c|}
\hline & Empreendimento \\
\hline Localização & Rio Grande do Sul (Brasil) \\
\hline Tipologia & Conjunto habitacional de aptos de $62,31 \mathrm{~m}^{2}\left(16\right.$ aptos) e $58,30 \mathrm{~m}^{2}(16$ aptos) cada \\
\hline Quantidade de unidades & 32 apartamentos \\
\hline Concreto utilizado nas paredes & Concreto auto-adensável $-25 \mathrm{MPa}$ \\
\hline Armação utilizada nas paredes & Tela soldada -Q283 - $10 \times 10 \mathrm{~cm}-\emptyset 6,3 \mathrm{~mm}$ \\
\hline Reforços nas armações & Reforço nas aberturas de portas e janelas \\
\hline Idade & 4 anos \\
\hline
\end{tabular}

Fonte: autoras(2019)

A Figura 1 demonstra a planta baixa do apartamento tipo, onde os imóveis da direita possuem suíte por isso a diferença na metragem quadrada.

Figura 1 - Planta baixa das edificações.

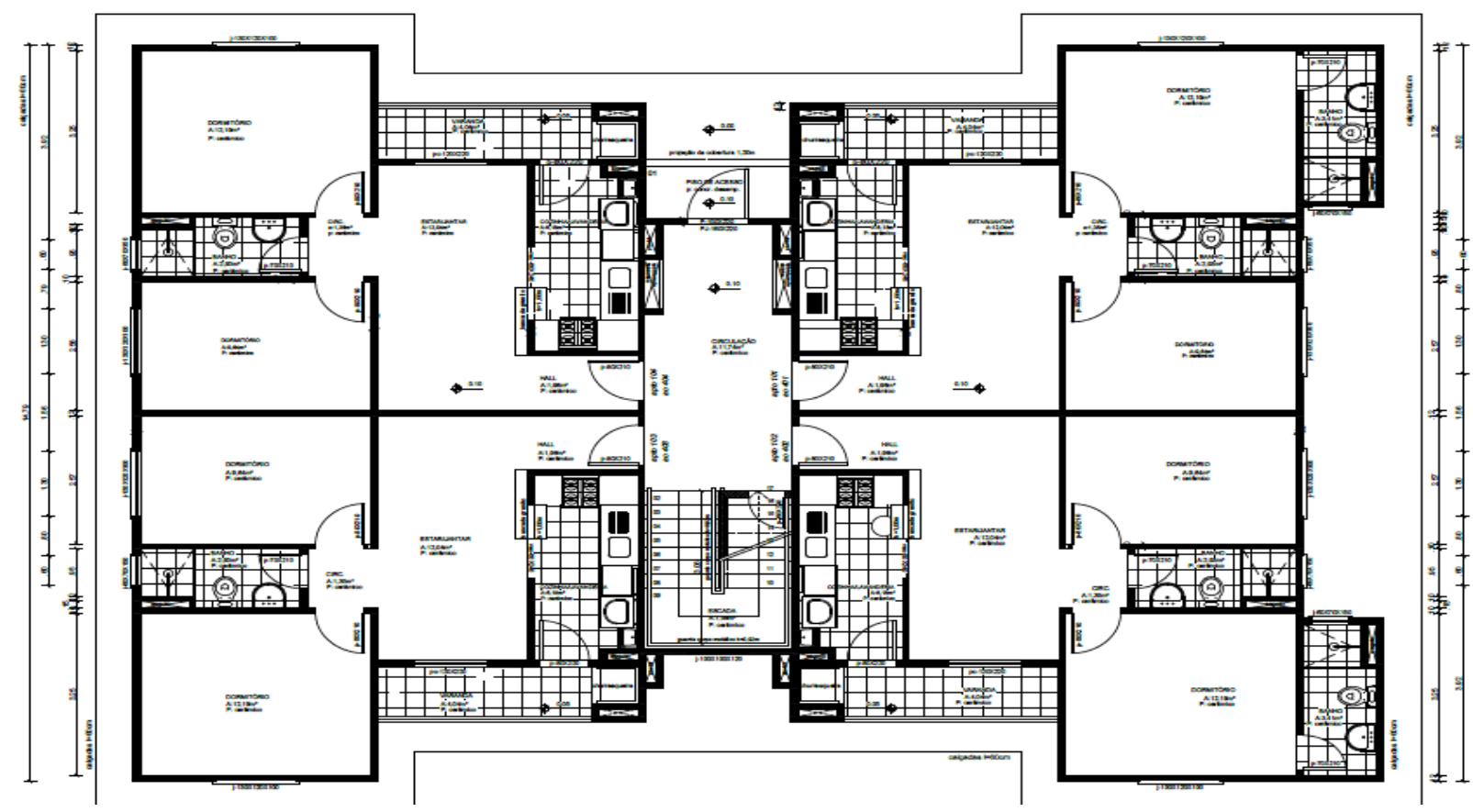

Fonte: PANNO(2019)

\section{RESULTADOS E DISCUSSÕES}

O estudo de caso contemplou um empreendimento construído com as vedações verticais no sistema parede de concreto moldado in loco.

Observa-se que quatro tipos de manifestações patológicas (fissuras nas aberturas de portas e janelas, fissuras no meio das paredes e fissuras no encontro entre paredes). Todas as outras manifestações patológicas aconteceram nos dois empreendimentos. $\mathrm{O}$ quadro 2 demonstra as principais fissuras encontradas.

Quadro 2 - Principal ocorrência de fissuras na edificação analisada.

\begin{tabular}{|l|l|l|}
\hline Localização & $\begin{array}{l}\text { Número de } \\
\text { ocorrências }\end{array}$ & $\%$ \\
\hline Fissuras nas aberturas de portas e janelas & 28 & 28 \\
\hline Fissuras no meio das paredes & 7 & 7 \\
\hline Fissuras na ligação de paredes de concreto com a laje & 32 & 32 \\
\hline $\begin{array}{l}\text { Fissuras nas paredes inferior nas esquadrias de } \\
\text { alumínio }\end{array}$ & 27 & 27 \\
\hline Fissuras 45 parede de canto externa & 6 & 6 \\
\hline Total & 100 & 100 \\
\hline
\end{tabular}


Fonte: autoras (2019)

A Figura 2 demonstra que a fissura quebrou a cerâmica, inicia no canto parede e continua até metade da parede. Esse defeito é resultado de tensões transmitidas à superfície cerâmica através das camadas inferiores. Para o aparecimento desta patologia, algumas situações são necessárias: base de assentamento muito forte, rígida (base de cimento); estrutura facilmente deformável, capaz de suportar pressões; estrutura com mobilidade ou capacidade de ceder em certas direções; estrutura sob tensão. Essas situações provocam o aparecimento de fissuras na base do revestimento (parede de concreto) que afloram na superfície do revestimento cerâmico. As fissuras do revestimento cerâmico são apenas o prolongamento das fissuras da estrutura. Um projeto de juntas mal executado pode contribuir para o agravamento do defeito. Como solução deve-se corrigir o substrato e repor a cerâmica.

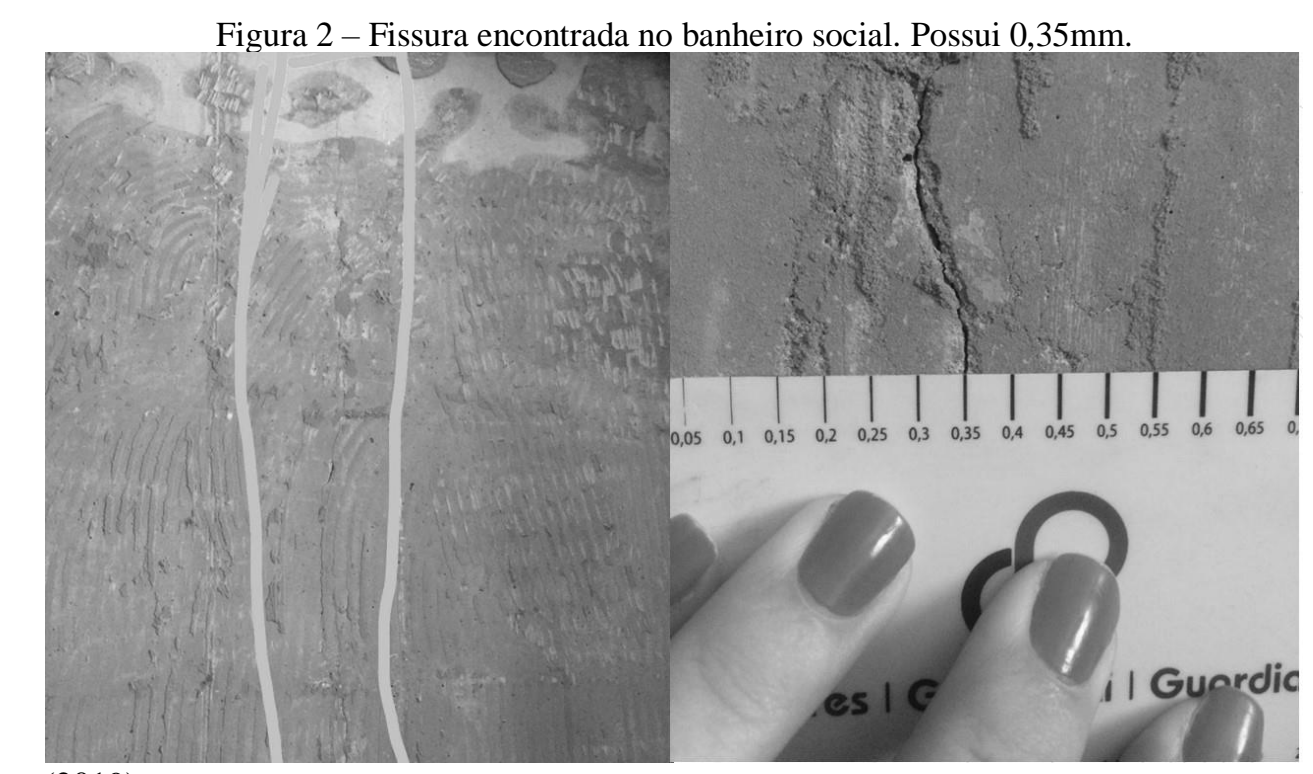

Fonte: autoras (2019)

Como pode ser observado na Figura 3, a fissura foi encontrada na divisa dos apartamentos.

Figura 3 - Fissura encontrada parede divisa entre apartamentos de $0,4 \mathrm{~mm}$.
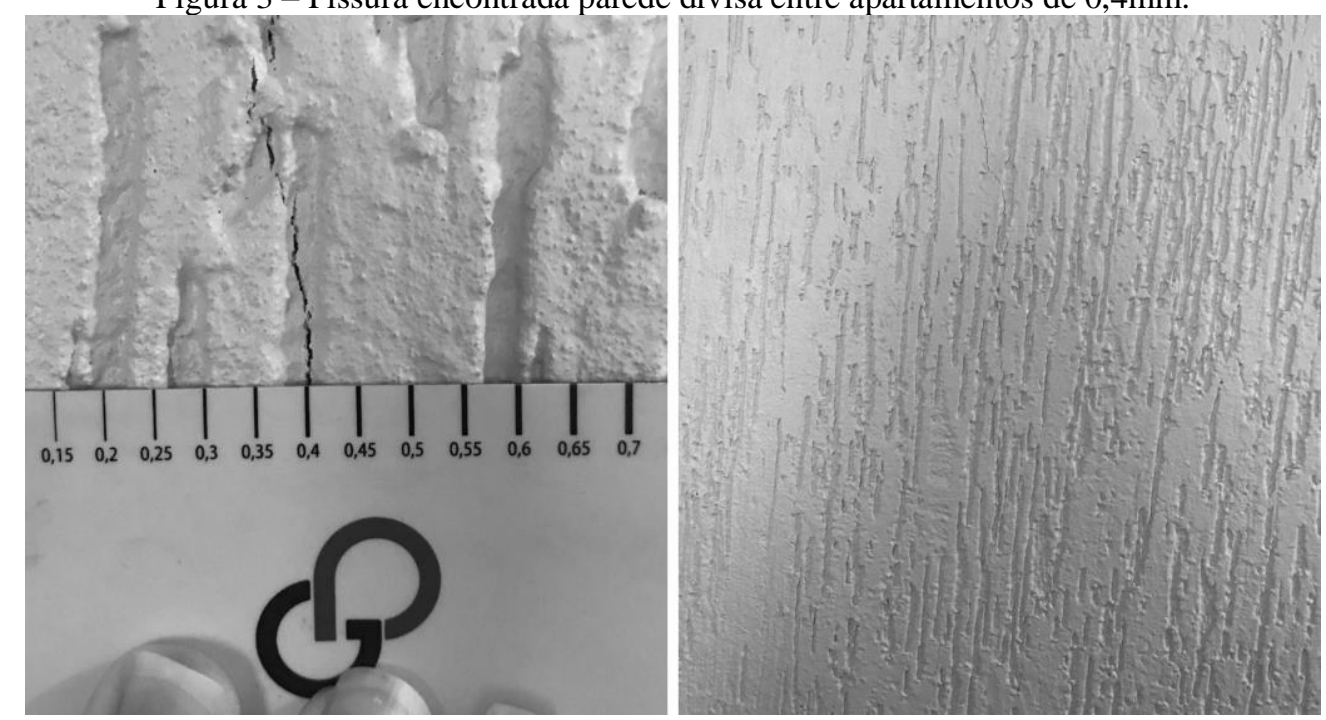

Fonte: autoras (2019)

Na Figura 4 o aparecimento de fissuras ao longo a laje mostra o caminho da tubulação, o mecanismo provável da ocorrência são tensões de tração ao longo da laje. A causa provável é a retração do concreto e a falta de cura e a origem possivelmente foi na execução. Ela é classificada como anomalia endógena. Recomendações para correção seria a demolição superficialmente área fissurada e refazê-la. 


\section{CBPAT 2020 \\ CONGRESSO BRASILEIRO DE PATOLOGIA DAS CONSTRUÇÕES \\ DE 15 A 17 DE ABRIL | FORTALEZA - CE}

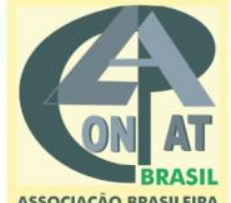

ASSOCIACĀO BRASILEIRA CONSTRUÇOES

Figura 4 - Fissura na laje saindo da luminária demonstra todo o trajeto da tubulação tem espessura de $0,05 \mathrm{~mm}$.

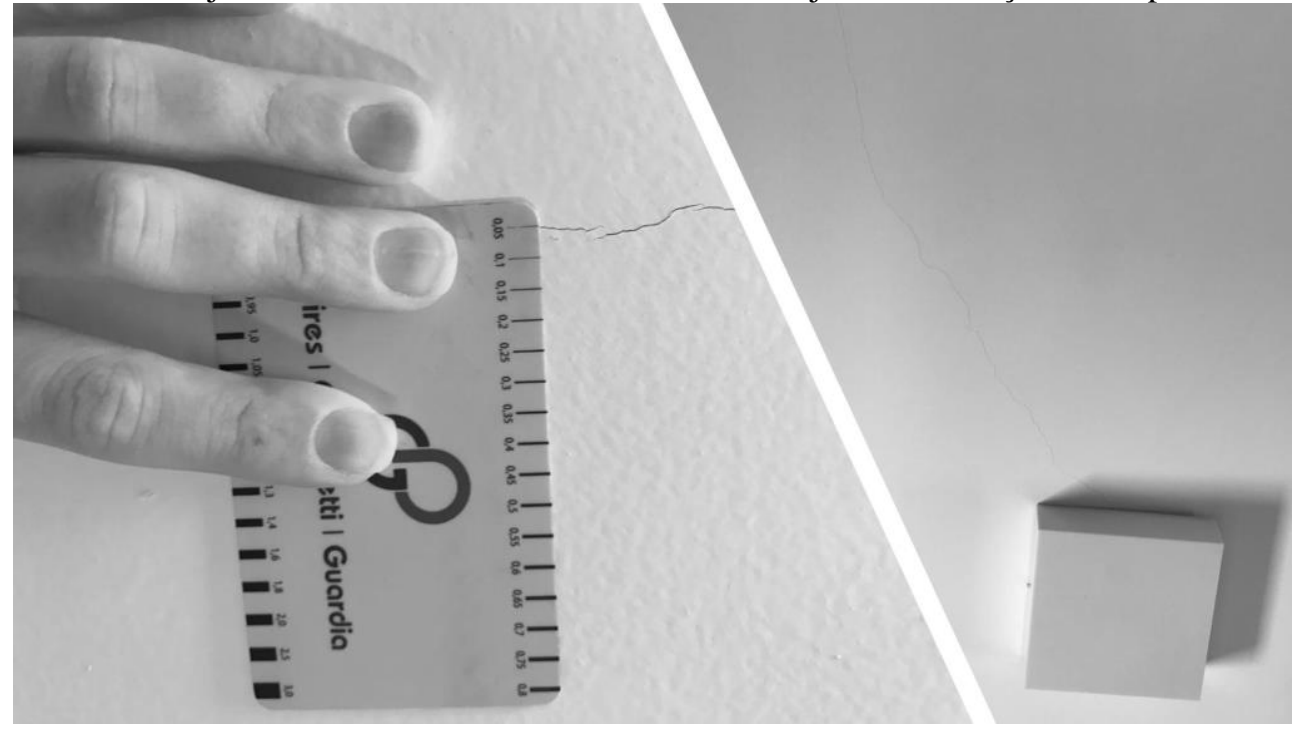

Fonte: autoras (2019)

A Figura 5 demonstra o sintoma de fissuras ao redor de aberturas de janelas em paredes de concreto, o mecanismo provável para essa manifestação é o acúmulo de tensões de tração nas aberturas provavelmente pela insuficiência de armadura de reforço ou posicionamento equivocado. A origem provável é o projeto estrutural assim como a execução da armadura de reforço. Ela é considerada uma anomalia endógena e é recomendado o reforço da armadura ao redor das aberturas.

Figura 5 - Fissura na laje saindo da luminária demonstra todo o trajeto da tubulação tem espessura de $0,05 \mathrm{~mm}$.
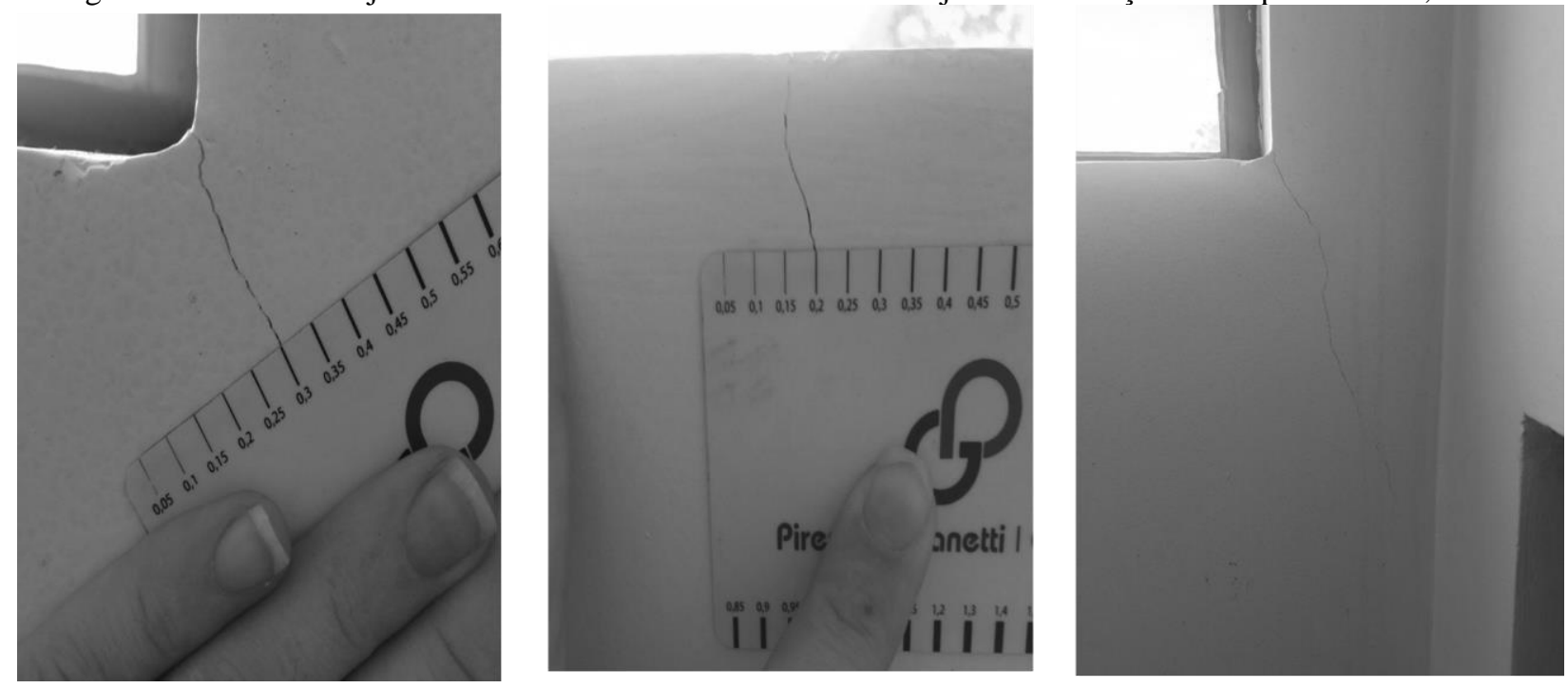

Fonte: autoras (2019)

A fissura à $45^{\circ}$ ao redor de aberturas de janelas, inicia com $0,3 \mathrm{~mm}$ e no seu final tem $0,2 \mathrm{~mm}$, demonstrando atividade.

Através da caracterização das manifestações patológicas pode-se chegar a conclusões em relação as origens e causas que levaram a ocorrências desses mecanismos de degradação, de modo a promover seu reparo e evitar que voltem a acontecer. 


\section{CONCLUSÕES}

Para usufruir das vantagens que o sistema construtivo de paredes de concreto oferece, é necessário que não haja retrabalho nem anomalias. É essencial, ter uma mão de obra qualificada e treinada tanto para execução como para acompanhamento e verificação dos serviços executados e a se executar.

Esse fato indica que a maioria das manifestações patológicas estão associadas as características de projeto, execução, materiais e manutenção, não estando necessariamente associadas ao sistema de vedação em parede de concreto. Isto é, a adoção de melhores práticas, por parte das construtoras, é o principal fator para diminuir a ocorrência dessas manifestações patológicas.

Apesar dessa patologia causar retrabalhos, o fato desse método construtivo ser ágil e sustentável compensa o custo causado por essas anomalias.

No empreendimento foi identificado um mesmo padrão de comportamento: as três manifestações patológicas de maior frequência são responsáveis por mais da metade das ocorrências identificadas.

Por fim, percebe-se no contexto da pesquisa que o sistema parede de concreto está sendo consolidado no mercado da construção civil brasileira; porém, as empresas ainda estão se adaptando em relação as melhores práticas de execução. 


\section{REFERÊNCIAS BIBLIOGRÁFICAS}

Associação Brasileira de Cimento Portland - ABCP (2008), "Parede de Concreto - Coletânea de ativos 2007/2008". São Paulo: ABCP, 2008.

ASSOCIACAO BRASILEIRA DE NORMAS TECNICAS. NBR 16055:2012: Parede de Concreto Moldada no Local Para a Construção de Edificações - Requisitos e Procedimentos. Rio de Janeiro, 2012.

Brasil (2017), "Relatório de avaliação da execução de programa de governo nº 66. Programa Minha Casa Minha Vida FGTS". Disponível em: . Acesso em 10 de novembro de 2019.

BRANDÃO. A.M. Qualidade e durabilidade das estruturas de concreto armado - aspectos relativos ao projeto. Dissertação (Mestrado) - , Universidade de São Paulo, São Carlos, 1998.

BRANDÃO A.M, PINHEIRO L.M, Qualidade e durabilidade das estruturas de concreto armado: aspectos relativos ao projeto. CADERNOS DE ENGENHARIA DE ESTRUTURAS, São Carlos, 1998.

CORSINI, R. (2011). Paredes Normatizadas. Téchne, São Paulo, 2011.

C.LORDSLEEM JR., V. Q.LIRA. Manifestações patológicas em paredes de concreto moldadas in loco: estudo de caso. XV Congreso Latinoamericano de Patología de Construcción y XVII Congreso de Control de Calidad en la Construcción CONPAT 2019, Vol. 2, PATOLOGÍA.2019.

HELENE, P.R.L. (1993). Durabilidade das estruturas de concreto armado. In: SIMPÓSIO EPUSP SOBRE ESTRUTURAS DE CONCRETO, 3., São Paulo, 1993. Anais. São Paulo, EPUSP/PEF. p.37-48.

MEHTA, P. K.; MONTEIRO, P. J. M. Concreto Microestrutura, Propriedade e Materiais- $2^{\mathbf{a}}$ Edição. Ed.: IBRACON. ISBN.:978-85-98576213. Português, p. 751, 2014.

NEVILLE, A. M.; BROOKS, J. J. Tecnologia do Concreto - 2ªdição. Ed.: Bookman. ISBN.: 978-85-8260-071-9. Português,p.448, 2013.

LIMA, G.A. Estudo de caso: melhorias na produção contínua de parede de concreto moldado in loco com fôrma de alumínio. Trabalho de diplomação como pré-requisito para diploma engenheiro civil. UFRGS, 2018.

SANTOS A. Paredes de concreto já dominam Minha Casa Minha Vida. Revista Itambé, 2016. Disponível em: . https://www.cimentoitambe.com.br/paredes-de-concreto-minha-casa-minha-vidal. Acessado em 11 dezembro de 2019.

THIYAGARAJAN, R.; Panneerselvam, V.; Nagamani, K. (2017), Aluminium formwork system in highrise buildings construction. International Journal of Advanced Research in Engineering and Technology, 8(6):29-41.

TUTIKIAN, Bernardo Fonseca. Proposição de um método de dosagem experimental para concretos auto-adensáveis. 2007. 163 f.. Tese (Doutorado em Engenharia Civil) - Programa de Pós Graduação em Engenharia Civil, Universidade Federal do Rio Grande do Sul, Porto Alegre.

TUTIKIAN, B. F. Prática Recomendada IBRACON - Concreto Autoadensável. Ed.: IBRACON. ISBN.:978-8598576-25-1. Português, p.76, 2015.

Vieira, L. B. (2014), "Projeto de paredes de concreto armado: apresentação das recomendações normativas e avaliação da influência das aberturas", Dissertação (Mestrado) - Escola Politécnica, Universidade Federal da Bahia, Salvador.

WENDLER, Arnoldo. Desempenho das Paredes de Concreto - Atendimento à NBR 15.575. 2017. Disponível em: https://www.construliga.com.br/blog/desempenho-das-paredes-de-concreto/. Acesso em 10 de dezembro de 2019. 